\title{
The role of undisclosed reserves in English open outcry auctions
}

Article

Accepted Version

Stevenson, S. and Young, J. (2015) The role of undisclosed reserves in English open outcry auctions. Real Estate Economics, 43 (2). pp. 375-402. ISSN 1540-6229 doi: https://doi.org/10.1111/1540-6229.12072 Available at https://centaur.reading.ac.uk/40904/

It is advisable to refer to the publisher's version if you intend to cite from the work. See Guidance on citing.

Published version at: http://onlinelibrary.wiley.com/doi/10.1111/1540-6229.12072/abstract

To link to this article DOI: http://dx.doi.org/10.1111/1540-6229.12072

Publisher: American Real Estate and Urban Economics Association

All outputs in CentAUR are protected by Intellectual Property Rights law, including copyright law. Copyright and IPR is retained by the creators or other copyright holders. Terms and conditions for use of this material are defined in the End User Agreement.

\section{www.reading.ac.uk/centaur}

\section{CentAUR}

Central Archive at the University of Reading

Reading's research outputs online 


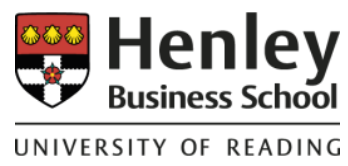

\section{The Role of Undisclosed Reserves in English Open Outcry Auctions}

Accepted for publication in Real Estate Economics

Simon Stevenson (University of Reading) \& James Young (University of Auckland) 


\title{
The Role of Undisclosed Reserves in English Open Outcry Auctions*
}

\author{
Simon Stevenson, University of Reading ${ }^{\dagger}$ \\ $\&$ \\ James Young, University of Auckland
}

\begin{abstract}
This study considers the role that reserve prices may play in residential property auctions. In comparison to much of the previous empirical work, this study has access to undisclosed reserve prices from English auctions. Consistent with theoretical arguments in the auction literature, the results obtained illustrate that whilst higher reserve prices increase the revenue obtained for the seller, they also reduce the probability of sale. The findings also highlight the importance of auction participation, with the number of individual bidders and the number of bids significant in most specifications.
\end{abstract}

JEL Codes: D44, R30

\footnotetext{
* The comments of the Editor, Crocker Liu, the anonymous referee's, Geoff Meen and seminar participants at University College Dublin, University of Reading and the University of Auckland are much appreciated. The help of Alison Stevenson in collating the data is also much appreciated.

${ }^{\dagger}$ Corresponding Author: Henley Business School, University of Reading, Whiteknights, Reading, RG6 6UD, UK. Tel: +44-118-378-4008, e-mail: s.a.stevenson@ reading.ac.uk, ${ }^{*}$ Department of Property, University of Auckland Business School, e-mail: james.young@auckland.ac.nz
} 


\section{The Role of Undisclosed Reserves in English Open Outcry Auctions}

\section{1: Introduction}

The empirical analysis of auctions has frequently been constrained by data limitations. This is especially so with respect to undisclosed reserve prices. As a result, it has often been difficult to empirically consider some of the key theoretical arguments regarding the impact and role of reserve prices. Using a dataset that includes information on the undisclosed reserve prices, this paper examines residential property auctions in Dublin, Ireland. The Irish market provides an interesting case to consider the dynamics of the auction process. English open outcry auctions are the main alternative form of sale mechanism to private treaty negotiated sales in the Irish market. In common with markets such as Australia (Lusht, 1994, 1996), auctions tend to be used at the higher end of the market. In contrast, markets such as the United States are characterized by a large proportion of auctioned properties representing distressed sales (DeBoer et al., 1992; Mayer, 1998 and McAfee at al. 2002). This obviously leads to differences in terms of the motivation of the sellers concerned and is of particular importance in terms of the reserve estimates.

The data set utilized in this study consists of 389 properties that were offered for sale through auction between 1998 and 2002. Importantly, this data includes information on variables often missing from existing empirical work, including the undisclosed reserve, the attendance at the auction, the number of bids and bidders and the individual auctioneer presiding. A key advantage in this dataset is that unlike many papers (e.g. Ong et al., 2005) we do not have to rely on proxies to capture the impact of different factors. In addition, due to the nature of the auction procedure followed in Ireland, we are largely considering willing sellers. Therefore, unlike papers such as DeBoer et al. (1992) and McAfee et al. (2002), our reserve estimate is based on perceived market value and not related to issues such as outstanding mortgage debt or unpaid tax.

One of the key features of the current study is the examination of how the reserve price impacts upon both the price obtained and the probability of sale at auction. Riley \& Samuelson (1981) illustrate that the imposition of a reserve will maximize revenue, 
a result that holds for either English or Dutch auctions. However, McAfee \& Vincent (1992) argue that whilst reserves should have a positive relationship with the sale price obtained, they will have a negative impact with respect to the likelihood of sale. The rationale behind this is that, naturally, if the vendor imposes a higher minimum price then he/she is less likely to witness a bid of that magnitude, hence a reduced probability of sale. However, if that level is achieved, then it is likely that the proceeds from the sale will be enhanced. Riley \& Samuelson (1981) also illustrate that the optimal reserve will be higher than the vendor's own valuation and furthermore that it is independent of the number of bidders. They also note that under an assumption that all bidders share a common cardinal utility function, the optimal reserve price is a declining function of the risk aversion of the vendor. This point is also argued by $\mathrm{Hu}$ et al. (2010), under an assumption of symmetric and independent private values. It is intuitive that more risk averse sellers will place greater attention on the risk of not selling ${ }^{1}$.

The remainder of the paper is structured as follows. The next section briefly considers some of the pertinent literature while section 3 details the data and methodological framework used in the study. The final two sections present the main empirical findings and provide concluding comments respectively.

\section{2: Auction Literature}

Whilst several papers have illustrated the importance of the reserve price in a theoretical context (Riley \& Samuelson, 1981; McAfee \& Vincent, 1992; and Hu et al., 2010), little empirical research has considered the issue. This is true not only in the specific instance of real estate but also across the broad auction literature. Often this has been simply due to the fact that reserve prices have not been available (e.g. Dotzour, et al., 1998; Toda et al., 1998; Ong et al, 2005; Stevenson et al., 2010). Because of these limitations, some papers, such as Ong et al. (2005), have used proxies in order to try and capture the impact. In this case the authors use a measure they refer to as the level of reserve price. This measure was defined as the percentage difference of an estimate of the property's market value relative to the opening bid $^{2}$. Furthermore, many of the papers that have been able to access reserve data have analyzed forced or distressed sales. For example, although DeBoer et al. (1992) find that an increased reserve reduces the probability of sale, the data analyzed consists of 
properties in Indianapolis sold due to the nonpayment of tax. As such tax sales have the reserve set at a level equal to the tax owed in Indiana, this frequently results in a reserve substantially less than the market value of the property. The study of McAfee at al. (2002) encounters a similar issue in estimating the optimal reserve price. In their case, observations consist of distressed sales conducted on behalf of the Federal Deposit Insurance Corporation (FDIC). Across 6 FDIC auctions, including a mix of open outcry and sealed bid, the sale price was, on average, $75 \%$ of the appraised value. In estimating the optimal reserve price they obtained an estimated lower bound also of $75 \%$. Given that at least in the majority of cases the winning bidder needed to have bid in excess of the reserve, it illustrates the low levels of reserves used by the FDIC. The finding that the optimal reserve should be in excess of those currently observed is also found in non-real estate papers such as McAfee \& Vincent (1992), Paarsch (1997) and Li et al. (2003).

An additional issue in the literature concerns the disclosure of the reserve price. Vincent (1995) argues that in a common-value auction, the non-disclosure of the reserve can increase the price obtained. The rationale for this argument is that disclosing the reserve may lead to non-bidding as potential participants may be discouraged if the reserve was either above or equal to their potential maximum bid. The argument in favor of non-disclosure is based on the premise of encouraging a greater number of bidders. As Vincent (1995) argues, if they did not participate then the information that their bids would have revealed is lost. It is effectively the same arguments relating to the impact of an increased number of bidders as will be discussed shortly.

Papers such as Eklof \& Lunander (2003) do however argue in favor of disclosure of the reserve in their investigation of residential apartment auctions in Stockholm. Using private values, thus assuming a motive of consumption, and assuming that the number of bidders is exogenous and known, the evidence provided shows that a strategy of non-disclosure yields lower expected revenue. It is important to note, however, that during the sample period considered, the Stockholm market was experiencing a downturn. Furthermore, the properties considered were not generally in prime areas therefore reducing the possibility of price appreciation, in the form of common values playing a major role. Importantly, as the authors note, they only had 
access to information contained in the winning bid. This therefore excludes information contained in other bids which should also be an important element in common values. Furthermore, the assumption that the number of bidders is exogenous and known eliminates the possibility that the disclosure of the reserve may lead to a reduction in the number of bids (Vincent, 1995). Goeree \& Offerman $(2002,2003)$ argue that revealing information about common value will increase revenue, as without this information there may be large degree of uncertainty regarding the value of the good/object. This uncertainty, added to by the infrequent nature of such auctions, leads to a loss of efficiency as less uncertainty being present will result in bidding being more aggressive. However, Goeree \& Offerman (2002, 2003) also illustrate that revenue will increase with the number of bidders and that the effect of the number of bidders is stronger than the effect of revealing more information. Therefore, if revealing information through the disclosure of the reserve reduces participation, it may lead to an overall loss of efficiency ${ }^{3}$.

The number of bidders has been a key component in the auction literature, particularly in those papers which have considered the likelihood of a successful auction sale. Whilst the role of the number of bidders in obtaining higher prices at auction is shown in papers such as Vickrey (1961), Holt (1979), Harris \& Raviv (1981) and McAfee \& McMillan (1987), empirical evidence for this is more thinly spread. Both nonproperty papers (Saidi \& Marsden, 1992; Chen et al., 2003) and those to have directly considered real estate (Ching \& Fu, 2003; Ong et al., 2005; Ooi et al., 2006) have all found some form of evidence that the number of bidders significantly impacts, in a positive sense, upon either the price obtained or the probability of a sale being achieved. Ong (2006) finds that the number of bidders plays a significant role in the price obtained even in the case of properties that were initially withdrawn at auction and subsequently sold privately. Whilst not directly examining the number of bidders, Stevenson et al. (2010) found that the role of turnout and the need to encourage as many participants as possible does play a role in how price information is communicated before an auction. Their findings illustrate that not only do auctioned properties sell at a premium compared to private sales, but that the listing price for auctioned properties is significantly lower than for properties sold privately. The authors argue that this may be attributed to agents using the advertised guide as a marketing tool where underpricing the auctioned properties may encourage a greater 
number of bidders to participate in the auction.

The role of bidders can also be related to the issue of market conditions, as it is likely that auctions undertaken during stronger conditions will see a higher number of potential bidders. Goeree \& Offerman $(2002,2003)$ explicitly argue that efficiency and therefore the revenue generated will be higher when more bidders enter the auction. Pesendorfer \& Swinkels (2000) note that a large number of bidders can lead to a resumption of efficiency, even in the case of a two-signal auction. Mayer (1995) argues that an increase in bidders also increases the likelihood of the participation of high-value bidders. In an auction context, this could be viewed as those with higher private values of the property concerned. The recent work of Chow et al. (2011) also notes this, arguing that auctions will be the preferred sale mechanism in a case where bidders with higher valuations participate ${ }^{4}$.

Although in a different context, Gilbert \& Klemperer (2000) illustrate that it may be more profitable for a seller to ration output, thus selling at a fixed price level at which demand exceeds supply, rather than selling at a higher price that clears the market. The underlying rationale relates to the idea that the offering of a lower price acts as an incentive for more buyers to enter the market. In the context of this research the above rationale has direct relevance. It can also be related to the arguments of Glower et al. (1998) who note that vendors convey information about their desire to sell the property through the listing price that is set.

The setting of the reserve price has parallels in the general housing literature in terms of listing prices. A number of papers have provided evidence that the setting of a guide price, in a private treaty context, has similar effects as with the reserve in an auction setting. Papers such as Haurin (1988), Mayer (1995) and Genesove \& Mayer (1997) argue that there exists a trade-off resulting from the setting of the guide price ${ }^{5}$. A higher guide will increase possible revenue, but it will also reduce the speed of arrival of bids and therefore generally lead to an increase in the amount of time the property is on-the-market. Genesove \& Mayer (1997) specifically illustrate this in the context of vendors with high loan-to-value ratios. Due to the need for increased revenue in order to comply with their mortgage financing obligations, they have a greater tendency to set a higher listing price. Merlo \& Ortalo-Magne (2004) also 
illustrate that the setting of the listing price affects the arrival of bids and thus the time-on-market. The longer the time-on-the-market then there is a fall in the 'arrival rate' of bids. In addition, it also has the impact that the probability that the listing price is adjusted increases and that there is a negative effect on both the amount of offers and the sale price relative to the listing price. However, it does, increase the probability that a match is successful. In this sense the findings can be related back to Mayer (1995) and the general advantage of a negotiated sale, in that it removes the time constraints present in an auction. This therefore allows vendors more time to find a bidder who matches their valuation of the property.

In a broader sense there is a major point of differentiation between list prices for private sales and list and reserve prices in an auction setting. As papers such as Haurin (1988), Horowitz (1992) and Yavas \& Yang (1995) argue, private treaty guide prices indicate what the reservation price of the seller is and. more importantly they indicate an upper bound to that reservation price. Unless a vendor is in a situation where competing bidders are present at the same point in time, the listing price effectively precludes the possibility of selling the property at a higher price. Indeed, it would be relatively rare that the list price is exceeded in a negotiated sale. However, not only will the sale price in a successful auction generally exceed the guide, but the reserve can be exceeded. This impact may be enhanced in the context of a sample such as ours where the reserve is undisclosed. In the context of our sample, listing and reserve prices therefore no longer act as an upper bound.

\section{3: Data}

The data analyzed in this paper consists of a total of 389 residential properties that were offered for sale through auction. The properties were all located in the Greater Dublin metropolitan area of Ireland and the auction date for each property was between 1998 and 2002. The data was obtained from one of the largest auctioneers/estate agents in Dublin and includes all information contained in their auction book ${ }^{6}$. The sample includes properties that were successfully sold at auction (198) and properties that were withdrawn (191). For 239 of the properties we also have the undisclosed reserve price ${ }^{7}$. In addition to price data we also have information on the number of bids, number of bidders, the attendance at the auction, whether 
multiple auctions were held that day, the auctioneer who conducted the auction and the location of the final bidder in the auction room. With regard to the multiple auctions dummy it should be noted that when multiple auctions took place it did not necessarily mean that the properties were similar, or substitutable. In many instances the properties concerned display a wide range of characteristics in terms of property type, guide price, size and location.

As is common in many countries, residential properties in Ireland may be sold either through private treaty or through auctions. In the case of properties sold through auction the form adopted is the first-price English open-outcry method. The decision as to the sale mechanism adopted is made by the vendor, in association with the agent, prior to marketing. It should be noted that not only are the agents involved with auction and private treaty sales the same firms, but that the agents act as the auctioneer for properties sold through that method. In terms of the choice of sale mechanism, certainly during the sample period considered in this paper, auctions were the sale method of choice by willing vendors of higher value properties. The extent of this can be seen in Stevenson et al. (2010) where over $60 \%$ of the properties in the highest value decile of their sample were sold through auction. Indeed, based on their sample it can also be seen that $43.66 \%$ of auctions were in the highest decile and $78.95 \%$ in the top three deciles by price. Whilst the Irish market, in common with Australia and New Zealand, see auctions being the preferred sale method at the premium end of the market, in markets such as the United States (DeBoer et al., 1992; Mayer, 1998 and McAfee at al. 2002) and Singapore (Ong et al., 2005, Ong 2006) a large proportion of properties sold at auction are distressed sales.

There is potential selectivity bias present in all studies of sale mechanisms in that the vendor's decision as to the mechanism selected may be associated with missing price affecting variables. This may result in differences in prices being wrongly attributed to the sale mechanism adopted rather than the omitted variable. Given that we are solely considering properties sold through auction we avoid this issue directly. Stevenson et al. (2010) do consider the issue in the context of the Irish market and in their sample of privately sold and auctioned properties do not find evidence of selectivity bias. 
Auction sales generally proceed through a relatively fixed process with a three to four week marketing period prior to the auction. The agent will generally include in the marketing material an estimate of the desired price, referred to as the guide or listing price. A number of issues arise with respect to the guide price. Firstly, it is not a binding commitment for either the vendor or the agent as to the final sale price. Secondly, it should be clearly noted that the listed price and the auction reserve are not one and the same. The guide price is merely the publicly available estimate of the value of the property as prepared by the agent/auction house. Effectively, the guide price is part of the marketing process for the property (Stevenson et al., 2010).

The auctioneer will agree with the vendor, generally on the day of the auction, a reserve price that will be the minimum acceptable value which the seller will consider. The reserve is not disclosed prior to the auction and, as will be illustrated in this paper, it is generally higher than the advertised guide price. This is unlike the practice in counties such as Australia where the reservation price is usually made public (Lusht, 1994, 1996). In the context of this data, the reserve price is not necessarily at the level at which the auctioneer opens the bidding. The level of reserve will in part be influenced by the auctioneer's assessment of the level of interest shown in the property during the marketing period. A factor that aids in the gauging of potential interest arises from the fact that successful bidders at auction are required to pay a non-refundable $10 \%$ deposit on the day of the auction and sign contracts agreeing that the sale be closed within six weeks of the auction date. In comparison, for negotiated private treaty sales the deposit is refundable up until the point when the contracts agreeing the sale are signed, which is typically 4 to 6 weeks after the price is agreed. Fees, commissions and transaction costs are however, identical for both sale methods. This means that it is imperative that potential purchasers undertake all necessary checks and surveys, both structural and legal, prior to the auction. It also means that financing arrangements need to be in place, particularly with respect to the $10 \%$ deposit, at the date of the auction. However, this process allows the auctioneer to gauge interest in the property, both in terms of the number of potential bidders, their seriousness and the possible price obtainable at auction. As with most English outcry auctions, if the reserve price is not met, then the vendor has the option of withdrawing the property from the market, with custom in Ireland dictating that the right of first negotiation lies with the highest bidder. 
The only point during the auction process when the reserve may be revealed is that on some occasions the auctioneer may declare that the property is 'on-the-market'. Whilst this is not a legal requirement, in the majority of cases in our sample the auctioneer did declare that the property was 'on-the-market' at some point after bidding had exceeded the reserve. However, it was not necessarily exactly at the reserve price. In a number of cases bidding had risen substantially above the undisclosed reserve prior to this declaration.

Prior to discussing the characteristics of the sample it is important to highlight two issues. Firstly, as previously noted, the majority of properties sold through auction in Ireland are at the higher end of the market. The second issue that requires noting is the sample period considered. The 1998-2002 period was one characterized by rapid upward movement of house prices (Stevenson, 2008). Previous papers, such as Mayer (1995), have illustrated the importance of controlling for market conditions. In the context of the current paper, whilst we do include time dummies in the specifications, there is less need to control for distinct market conditions. However, the results are indicative of a strong upward market and may not necessarily apply in the context of weaker market conditions. In addition, the broader comments of Mayer (1995) with respect to the optimality of auctions versus negotiated sales in boom markets needs to be taken into account. Whilst generally the model of Mayer (1995) argues in terms of the optimal nature of negotiated sales, he does note that it assumes that a seller cannot adjust the price in the face of two bidders willing to pay the guide price. Therefore, in strong upward markets, auctions may provide an opportunity to maximize revenue further as bidders can raise prices in excess of the guide price.

With regard to property specific variables, data is available for the number of bedrooms, number of bathrooms and whether the property had parking facilities. In the absence of reliable square footage data, the bedroom and bathroom variables act as a proxy for the size of the property. In all of the tests conducted we control for the time of sale and the location and type of the property. Given the small sample it was not feasible to use time dummies at a greater frequency than annual. For location, the properties are divided into the Central City, South City, North City, South County and Periphery of Dublin. The Central City is defined by the postcodes (zip codes) D1, D2, 
D7 and D8. The remaining areas within the City of Dublin are divided based on the River Liffey into North and South. The use of even numbered postcodes south of the river and odd numbered ones north of the river makes this divide straightforward. South County Dublin contains all areas within the County of Dublin south of the River Liffey but not formally within the City of Dublin. The peripheral grouping contains all remaining areas in the County of Dublin and also those properties in neighboring countries that can viewed as part of the greater metropolitan area, including parts of Wicklow, Kildare, Meath and Louth. Property type variables are included for the following house types: detached, semi-detached house, bungalow (ranch), terrace/mews and apartment (condominium).

Table 1 provides summary statistics for the sample. Panel's A through C display the average and median prices reported, whilst Panel D reports counts for the dummy variables used. Of the 389 properties analyzed, 198 successfully sold at auction whilst the remaining 191 were withdrawn. It can also be seen that the spread of the sample across property type is relatively even, with only the apartment sector seeing a small number of properties sold through auction (23). If one compares the breakdown to that in Stevenson et al. (2010) it is relatively similar. However, as one would possibly expect given that our sample is restricted to properties sold through auction, we observe a slightly higher proportion in detached houses, bungalows and apartments. In comparison, our sample has a slightly lower smaller representation from semidetached houses and terrace/mews properties. The location of properties is dominated by two key submarkets, namely South City and South County Dublin. These are the two most highly priced submarkets in Greater Dublin and confirm the comment made earlier that auctions were used primarily at the premium end of the market, particularly during the period covered in this sample. The dummy variables with respect to the location within the room and the auctioneer are defined as follows. In relation to the location of the winning bid, this is defined quite broadly as being at the front, center or rear of the room. For the auctioneer variable we have details on the individual person who conducted the auction. Three auctioneers conducted the majority of the proceedings and presided over far more auctions than others. These three auctioneers are denoted as 1, 2 and 3 respectively. The dummy variable Auctioneer 4 combines all remaining auctioneers. 
Table 1 also reports the main summary statistics from the data, whilst Table 2 details the average of the percentage differences across the different prices for the individual properties $^{8}$. From the two tables it can be seen that not only was the average sale price achieved above the reserve, but that the reserve itself was on average higher than the guide price 9 . For those properties sold at auction for which complete information is available as shown in Panel $C$, the average guide price was $€ 341,700$. In contrast the average undisclosed reserve was $€ 394,943.33$ and the average sale price was $€ 450,326.67$. This highlights two issues. Firstly, it would appear that vendors and auction houses discounted the listing prices, possibly in order to attract additional participants to the auction, consistent with the findings of Stevenson et al., (2010). Secondly, the fact that sale prices are on average higher than the reserve would indicate that the auction process does add an element of value to the sale process.

These effects can also be seen from the statistics displayed in Table 2 which reports the percentage differences across the guide, opening bid, reserve and sale prices. Here it can be clearly seen that on average the reserve was $15.15 \%$ above the guide price. Furthermore, in only four out of 240 cases was the reserve set below the guide. Indeed, the high proportion found here is repeated elsewhere. On average the achieved sale price was $14.18 \%$ above the reserve, with only six out of 150 observations being negative, and $31.97 \%$ above the listing price, with only three negative observations. The fact that not only is the average sale price higher than the reserve but that a positive result is achieved in virtually all of the cases highlights the key difference between auction and private treaty sales noted earlier. Whilst the setting of the reserve higher than the guide may initially appear to be in line with the argument of Riley \& Samuelson (1981) in that the optimal reserve should be higher than the vendors own valuation, it is important to remember that the guide is not necessarily a pure estimate of valuation. It is also of interest to consider the behavior of the auctioneers by looking at the opening bids. The auctioneer can open the bidding at any price and is not constrained by either the advertised listing price or the undisclosed reserve. Table 2 shows that on average auctioneers open the bidding $6.59 \%$ below the advertised guide price, a figure equivalent to the reserve being $24.48 \%$ higher. Indeed, this trend was followed with over $70 \%$ of the observations seeing the opening bid below the guide. In only four out of 199 observations was the bidding opened above the reserve. The overall finding was that the average 
percentage price movement from the opening bid to the sale price was in excess of $40 \%{ }^{10}$.

\section{4: Empirical Analysis}

\section{1: The Probability of Sale}

The empirical analysis consists of two primary components. This first section involves an analysis of the probability of a successful sale, whilst the second examines and models the sale premiums ${ }^{11}$. To consider those features and characteristics of the auction process on the success of the auction, a probit model is estimated where the dependent variable is a binary variable taking the value of unity if the property was sold and zero otherwise. The model can be specified as follows:

Outcome $=f($ baths, beds, parking, Type, Location, Time, attendance, bidders, bids, multiple, Auctioneer, Room, previous, order)

The explanatory variables include a variety of both property specific factors and variables that specifically refer to the auction. In the above equation variables notated to in bold refer to groups of variables. The property specific variables include the number of bathrooms, bedrooms and a dummy indicating whether the property had parking facilities. Groups of dummies were included to capture the impact of property type, location and the year of sale. The base property was a bungalow, located in North City Dublin, sold in 2000. Whilst the importance of these would obviously impact upon both the listing and sale prices, papers such as DeBoer et al. (1992) and Ong et al. (2005) show that factors such as location can also impact upon the probability of sale. The auction variables included relate to the attendance at the auction, the number of bidders, the number of bids and whether multiple auctions were held that day. These variables obviously relate to the large literature discussed previously that has illustrated the importance of bidders in both obtaining higher prices at auction and leading to an increased probability of sale ${ }^{12}$. Ong et al. (2005) explicitly highlights the role of the number of the bidders with the turnout variable positive and statistically significant at conventional levels in a probit model of Singaporean residential property auctions. The detailed data utilized here allows for the inclusion of not only overall attendance figures but also the specific number of 
bids and bidders. Given the possible similarity between these two variables (bids and bidders) we checked the correlation between the two. However, we observe that it is only 0.44 . When looking at the underlying data it is clear that a wide variety of circumstances do exist. These include extended auctions in terms of bids but where the auction is dominated by a small number of bidders, frequently only two. We also observe cases where the opposite occurs with a relatively large number of bidders entering a limited number of bids, often just one.

In addition to the above variables, dummy variables relating to the auctioneer who presided over the sale, a dummy variable as to whether the previous auction that day had resulted in a sale and the ordering of the auction in the day were included. The information relating to the location of the winning bidder was grouped into categories of front, center, and rear with the front of room dummy excluded from the estimated model.

The results from the model are reported in Table 3. Model I refers to the base specification. Models II, III and IV are augmented specifications that in addition to the core variables add the following. Model II includes the Guide Price. The rationale here is that a lower guide may lead to an increased probability of sale, an argument related to that used by Stevenson et al. (2010) with respect to agents using the listing price as a marketing tool. Model III includes the Reserve Price and also the percentage premium of the reserve over the guide. This relates to the large volume of literature concerning the role of the reserve in both having a positive impact upon revenue but likewise having a negative impact upon the likelihood of sale (Riley \& Samuelson, 1981; McAfee \& Vincent, 1992; Hu et al., 2010) ${ }^{13}$. The final specification, Model IV, includes the Opening Bid and the premium of the reserve over it.

The results, reported in Table 3, provide empirical evidence to support a number of the theoretical arguments presented. As would be anticipated, the majority of the property specific variables are not significant. This is intuitive as the primary area where these variables come into play is in terms of the price. However, as with the Ong et al. (2005) study, we do find significant coefficients with respect to some of the location variables. It is shown in three of the four specifications that properties in the 
South City display a significantly greater probability of sale. Furthermore, properties in South County Dublin do likewise in Model IV. This illustrates that while the location obviously plays an important role in the price of the property, it also influences the success of the auction. Interestingly, the South City and South County of Dublin are the prime residential areas.

In relation to the variables concerned with bids, all specifications report significant findings. The Number of Bids and the Number of Bidders both significantly increase the probability of sale in the first three models, whilst the number of bids is also significant in Model IV. This provides supporting evidence for the theoretical arguments relating to the importance of bidders. While Auction Attendance is not itself significant, the dummy variable relating to whether multiple sales took place is in all but Model IV. This would imply that attendance does perhaps play a role, although as noted previously the properties auctioned on the same day frequently displayed characteristics that were quite divergent. Interestingly, the dummy variable concerned with the winning bidder being in the center of the room was significant in two of the four models. In both Models II and III, this increased the probability of sale to a statistically significant extent. The augmented specifications all provide an element of significant findings. In Model II, the Guide Price is found to be significantly negative, implying that an increase in the listing price significantly reduces the probability of sale. It could be argued that it plays an important role, as implied by Stevenson et al. (2010), in the marketing of the property and the encouragement of participation in the auction. The general housing literature does find a parallel finding in that an increase in private treaty listing prices reduces the speed at which bids arrive and increases the time-on-the market (e.g. Haurin, 1988; Mayer, 1995; Genesove \& Mayer, 1997; Merlo \& Ortalo-Magne, 2004).

Model III incorporates the Reserve Price into the specification ${ }^{14}$. This is one of the key elements of this paper given the rarity at which information pertaining to undisclosed reserves is available for empirical testing. It was found that the reserve has a significant negative coefficient with respect to the probability of sale, albeit marginally. This provides a level of empirical support for the theoretical arguments put forth by Riley \& Samuelson (1981), McAfee \& Vincent (1992) and Hu et al. (2010). Ong et al. (2005) were forced to use a proxy for the reserve; however it did 
not result in significant findings. The final variables are the Reserve-to-Guide premium in Model III and the Opening Bid and Reserve-to-Opening Bid premium in Model IV. Whilst the percentage premium of the Reserve to Guide is negative it is not so at significant levels. Likewise, the Opening Bid is not statistically significant. It may be, in this case, that bidders are very aware that the opening bid provides limited information. As previously reported on average the opening bid was $6.59 \%$ lower than the advertised guide. Therefore, bidders may simply accept that the auctioneer will start the bidding at a low level in order to encourage initial bids. However, while the Opening Bid itself was not significant, the premium of the reserve over it was with a significant negative coefficient found. This is also intuitive as this measure captures the increase in the bidding necessary for the property to be sold. It also provides additional support for the previous results with respect to the negative relationship between the reserve and the likelihood of sale. While the initial coefficient concerning the reserve itself was only marginally significant at conventional levels, the premium of the reserve over and above the opening bid is highly significant, at a $99 \%$ level.

\section{2: Analysis of Sale Premiums}

The second element of the empirical analysis considers an analysis of the sale premiums. Percentage changes of the sale price relative to the opening bid, guide price and undisclosed reserve are analyzed in turn. The models are specified in a similar manner to those previously discussed, whilst the results are reported in Table 4.

Premium $=f$ (baths, beds, parking, Type, Location, Time, attendance, bidders, bids, multiple, Auctioneer, Room, previous, order)

Given the nature of the dependent variable in these cases, the interpretation of the findings has to be done so carefully, as the results may not necessarily imply a higher sale price obtained. For example, the findings with respect to auctioneer dummy variables are a case in point. In the analysis of the Sale-to-Opening Bid, Auctioneer 2 and Auctioneer 3 are both negative and significant. Furthermore, Auctioneer 3 reports a significant positive coefficient when the Sale-to-Guide Price is modeled as does the

Auctioneer 2 variable in the Sale-to-Reserve specification. With regard to the 
premium over the opening bid, these findings may simply imply that the second and third auctioneers tended to open the bidding at a higher price. It does not necessarily imply that they sold the properties for lower prices. Likewise, given that the auctioneer will be involved throughout the sale process and therefore have a role in the setting of the guide price, a similar interpretation could be lent to the second model. In this case a significant positive result was found with respect to Auctioneer 3. This could imply that the third auctioneer tended towards a lower guide price, perhaps due to the previously evidenced role that the guide can play. Furthermore, this viewpoint would be consistent with a counter interpretation in the case of the third model. As the reserve price will be set by the auctioneer in conjunction with the vendor and will be the undisclosed minimum acceptable price to the seller, there is less room for this variable to be affected by the strategies adopted by the auctioneer. Therefore, the significant positive coefficient reported in relation to Auctioneer 2 when the Sale-to-Reserve premium is modeled could be interpreted as an indication of the skill of the auctioneer in question in achieving a higher sale price specification.

A number of other variables provide significant findings in the analysis of the sale premiums. It is of interest that in a number of cases property specific variables report significant coefficients. This is true of the Bedrooms (positive) and Semi-Detached (negative) variables in the modeling of the Sale-to-Opening Bid and the Terrace/Mews (negative), Detached (negative), South City (positive) when the Saleto-Guide premium is examined. Similarly with the auctioneers finding, the analysis of the results require carful interpretation. In some cases it may be that the auction process leads to a premium that can be attributed to certain characteristics. This may be true, for example, in terms of the positive coefficient for the South City. As seen from three of the probit model specifications this variable did have a significant positive effect on the likelihood of sale. However, it is interesting that no such property specific variables are significant in the case of the premium over the reserve price. Since the reserve price is the minimum acceptable price for the seller it may be that it is a more accurate measure of the anticipated price than either the opening bid or guide. In contrast, to varying degrees and in slightly different contexts, both the opening bid and guide prices are part of the auction process and may be adapted by the agent/auctioneer in order to encourage participation and bidding. Therefore, information other than that which reflects the 'true' estimated value of the property 
may be incorporated into them.

A number of the year dummies are also significant in the various specifications. Specifically, 1999 is significantly positive when looking at the premium over the guide price, while a similar result is reported for 2002 when the reserve price is considered. Again these findings may reveal more about the base price rather than the achieved sale price. It may be that guide prices were underestimated in 1999, while sellers and auctioneers were similarly cautious with reserve prices in 2002. This explanation is somewhat intuitive given the market conditions in Ireland in this period. The fast rate of house price appreciation in the late nineties may have meant that despite the short time horizon under consideration here, the market was moving so fast in 1999 to give the impression of an exaggerated Sale-to-Guide premium. Likewise, the brief respite in the market that occurred in 2001 may have resulted in agents and sellers being more cautious in their assessment of achievable prices in $2002^{15}$.

One of the key elements across all three models is the role that bidders play in the auction process. For each specification both the Number of Bids and the Number of Bidders is positive and significant, supporting the existing literature in relation to the importance of participation. The results indicate that increased participation results in a significantly higher sale premium, irrespective of whether the base figure is the opening bid, guide price or reserve. In addition, when considering the Sale-Reserve premium, overall Auction Attendance is also positive and significant. On an associated point, the dummy relating to whether the previous auction that day had been successful was significant in the Sale-Reserve specification. This implies that behavioral elements may come into play and that a positive impact from the success, or otherwise, of previous auctions is an important element in achieving a premium.

The final empirical results expand upon the analysis thus far presented to consider the impact a higher reserve has upon the sale price obtained. The specification utilizes the same variables as in the preceding analysis with the dependent variable modeled as the $\log$ of the sale price, for those properties successfully sold at auction. In addition to the variables used in the analysis of the sale-premiums, the premium of the reserve over and above the guide price was also added. The premium is estimated as the 
percentage difference between the undisclosed reserve with reference to the publicly disclosed guide price. The results from this model are displayed in Table 5. Prior to discussing the key variable of interest, it is worth noting some of broader findings. Given that the variable being modeled is the achieved price, it is not surprising that key determinants of house prices are achieving coefficients of statistically significant levels in this model. For example, the number of bedrooms, doubling as a proxy for property size, is positive and significant, as is the South City of Dublin dummy. The time dummies illustrated the strong upward movement in prices during the sample period. The significant positive coefficient with respect to Auctioneer 1 needs careful interpretation. While it would appear to initially imply that Auctioneer 1 displays enhanced skill in obtaining a higher sale price, it is more likely that the that the auctioneer in question tended to preside over those auctions involving the most highly valued properties ${ }^{16}$.

In relation to the reserve over guide premium, a statistically significant positive coefficient was found. This would indicate that the higher the reserve price was, relative to the advertised guide, the higher the achieved sale price. This is consistent with the theoretical arguments presented in papers such as Riley \& Samuelson (1981) and McAfee \& Vincent (1992). As noted in the introduction, Riley \& Samuelson (1981) argue that reserves will maximize revenue, whilst McAfee \& Vincent (1992) note that that reserves should have a positive relationship with the sale price obtained. The results obtained previously with respect to the probability of sale, also support McAfee \& Vincent (1992). Therefore, our findings support their notion that while a higher reserve may lead to an increased sale price, at the same time it will reduce the likelihood of sale. As previously mentioned, the rationale underpinning this argument is that if the vendor imposes a higher minimum price, then proceeds from any sale will be enhanced. However, at the same time a higher reserve will reduce the likelihood of the vendor receiving a bid of an acceptable level, reducing the probability of sale.

\section{5: Conclusion}

One of the common problems that the empirical literature on auctions has encountered is the unavailability of key elements of data. In particular, information concerning 
issues such as the number of bids/bidders and the undisclosed reserve price is often not available, leading to either the exclusion of this variable from empirical work or the use of proxies. This problem has also led to a disparity between the rich vein of theoretical auction papers and the relatively limited number of empirical studies in the field. This paper has an advantage in that the data set available provides a rich vein of information relating to the auction process. The results reported are broadly supportive of the theoretical auction literature. The impact of the undisclosed reserve plays an important role with evidence that while it may increase the revenue obtained from the auction, a higher reserve also reduces the probability of sale. Throughout the analysis, the role of auction participation is highlighted in the findings that the number of bidders/bids is generally significant not only in the probability of sale at auction but also with respect to premium of the sale price achieved.

There are however, a number of issues and areas of interest that we do not consider. One important element that we do not currently examine is that of optimal reserve prices. Given the availability of the actual reserve prices, a comparison between those and theoretically optimal ones would be of great interest. This is an area that the authors are currently considering. A further area where this research is being expanded upon relates to the bids. The current paper solely considers the number of bids and bidders. However, the data does allow an empirical consideration of the bid sequencing. Given the different nature of housing auctions compared to arenas such as online internet auctions this provides an interesting line of inquiry. 


\section{References}

An, Y., Hu, Y. \& Shum, M. (2010). Estimating First-Price Auctions with an Unknown Number of Bidders, Journal of Econometrics, 157, 328-341.

Anglin, P.M. Rutherford, R. \& Springer, T.A. (2003). The Trade-off Between the Selling Price of Residential Properties and The Time-on-the-Market, Journal of Real Estate Finance and Economics, 26, 95-111.

Arnold, M.A. (1999). Search, Bargaining and Optimal Asking Prices, Real Estate Economics, 27, 453-482.

Bajari, P. \& Hortacsu, A. (2003). The Winner's Curse, Reserve Prices, and Endogenous Entry: Empirical Insights from eBay Auctions, RAND Journal of Economics, 34, 329-355.

Bajari, P. \& Hortacsu, A. (2004). Economic Insights from Internet Auctions, Journal of Economic Literature, 42, 457-486.

Chen, A., Liaw, G. \& Leung, M. (2003). Stock Auction Bidding Behavior and Information Asymmetries, Journal of Banking \& Finance, 27, 867-889.

Chen, Y. \& Rosenthal, R.W. (1996a). Asking Prices as Commitment Devices, International Economic Review, 36, 129-155.

Chen, Y. \& Rosenthal, R.W. (1996b). On The Use of Ceiling-Price Commitments by Monopolists, Rand Journal of Economics, 27, 207-220.

Ching, S. \& Fu, Y. (2003). Contestability of Urban Land Market: An Event Study of Government Land Auctions in Hong Kong, Regional Science and Urban Economics, 33, 695720.

Chow, Y.L., Hafalir, I. \& Yavas, A. (2011). Auction versus Negotiated Sale: Evidence form Real Estate Sales, working paper, Department of Real Estate, National University of Singapore.

DeBoer, L., Conrad, J. \& McNamara, K. (1992). Property Tax Auction Sales, Land Economics, 68, 72-82.

Dotzour, M.G., Moorhead, E. \& Winkler, D.T. (1998). The Impact of Auctions on Residential Sales Prices in New Zealand, Journal of Real Estate Research, 16, 57-71.

Eklof, M. \& Lunander, A. (2003). Open-Outcry Auctions with Secret Reservation Prices: An Empirical application to Executive Auctions of Tenant Owner's Apartments in Sweden, Journal of Econometrics, 114, 243-260.

Genesove, D. \& Mayer, C.J. (1997). Equity and Time to Sale in the Real Estate Market, American Economic Review, 87, 255-269. 
Gilbert, R.J. \& Klemperer, P.D. (2000). An Equilibrium Theory of Rationing, Rand Journal of Economics, 86, 180-94.

Glower, M., Haurin, D.R. \& Hendershott, P.H. (1998). Selling Time and Selling Price: the Influence of Seller Motivation, Real Estate Economics, 26, 719-740.

Goeree, J.K. \& Offerman, T. (2002). Efficiency in Auctions with Private and Common Values: An Experimental Study, American Economic Review, 92, 625-643.

Goeree, J.K. \& Offerman, T. (2003). Competitive Bidding in Auctions with Private and Common Values, The Economic Journal, 113, 598-613.

Guerre, E., Perrigne, I. \& Vuong, Q. (2000). Optimal Nonparametric Estimation of First Price Auctions, Econometrica, 68, 525-574.

Haile, P.A. \& Tamer, E. (2003). Inference with an Incomplete Model of English Auctions, Journal of Political Economy, 111, 1-51.

Harris, M. \& Raviv, A. (1981). A Theory of Monopoly Pricing with Demand Uncertainty, American Economic Review, 71, 347-365.

Haurin, D. (1988). The Duration of Marketing Time of Residential Housing, Journal of the American Real Estate and Urban Economics Association, 16, 396-410.

Hendricks, K., Pinkse, J. \& Porter, R. (2003). Empirical Implications of Equilibrium Bidding in First-Price, Symmetric, Common-Value Auctions, Review of Economic Studies, 70, 115145 .

Holt, C. (1979). Uncertainty and the Bidding for Incentive Contracts, American Economic Review, 69, 697-705.

Horowitz, J.L. (1992). The Role of the List Price in Housing Markets: Theory and Econometric Model, Journal of Applied Econometrics, 7, 115-129.

Hu, A., Matthews, S.A. \& Zou, L. (2010). Risk Aversion and Optimal Reserve Prices in First and Second Price Auctions, Penn Institute for Economic Research Working Paper 10-001.

Knight, J.R. (2002). Listing Price, Time on Market, and Ultimate Selling Price: Causes and Effects of Listing Price Changes, Real Estate Economics, 30, 213-237.

Knight, J.R., Sirmans, C.F. \& Turnbull, G.K. (1998). List Price Information in Residential Appraisal and Underwriting, Journal of Real Estate Research, 15, 59-76.

Li, T., Perrigne, I. \& Vuong, Q. (2002). Structural Estimation of the Affiliated Private Value Auction Model, RAND Journal of Economics, 33, 171-193.

Li, T., Perrigne, I. \& Voung, Q. (2003). Semi-Parametric Estimation of the Optimal Reserve Price in First-Price Auctions, Journal of Business and Economic Statistics, 21, 53-64. 
Lusht, K. (1994). Order and Price in a Sequential Auction, Journal of Real Estate Finance \& Economics, 8, 259-266.

Lusht, K. (1996). A Comparison of Prices Bought by English Auctions and Private Negotiations, Real Estate Economics, 24, 517-530.

McAfee, P. \& McMillan, J. (1987). Auctions with a Stochastic Number of Bidders, Journal of Economic Theory, 43, 1-19.

McAfee, R. P., Quan, D.C. \& Vincent, D.R. (2002). How to Set Minimum Acceptable Bids, with an Application to Real Estate Auctions, Journal of Industrial Economics, 50, 391-416.

McAfee, R. P. \& Vincent, D. (1992). Updating the Reserve Price in Common-Value Auctions, American Economic Review, 82, 512-518.

Maskin, E. \& Riley, J. (1984). Optimal Auctions with Risk-Averse Buyers, Econometrica, 52, $1473-1518$.

Mayer, C. (1995). A Model of Negotiated Sales Applied to Real Estate Auctions, Journal of Urban Economics, 38, 1-22.

Mayer, C. (1998). Assessing the Performance of Real Estate Auctions, Real Estate Economics, 26, 41-66.

Merlo, A. \& Ortalo-Magne, F. (2004). Bargaining over Residential Real Estate: Evidence from England, Journal of Urban Economics, 56, 192-216.

Ong, S.E. (2006). Price Discovery in Real Estate Auctions: The Story of Unsuccessful Attempts, Journal of Real Estate Research, 28, 39-59.

Ong, S.E., Lusht, K. \& Mak, C.Y. (2005). Factors Influencing Auction Outcomes: Bidder Turnout, Auction Houses and Market Conditions, Journal of Real Estate Research, 27, 177191.

Ooi, J.T.L., Sirmans, C.F. \& Turnbull, G.K. (2006). Price Formation under Small Numbers Competition: Evidence from Land Auctions in Singapore, Real Estate Economics, 34, 51-76.

Paarsch, H.J. (1997). Deriving an Estimate of the Optimal Reserve Price: An Application to British Columbia Timber Sales, Journal of Econometrics, 78, 333-357.

Paarsch, H.J. \& Hong, H. (2006). An Introduction to the Structural Econometrics of Auction Data, MIT Press: Cambridge, MA, USA

Pessendorfer, W. \& Winkels, J.M. (2000). Efficiency and Information Aggregation in Auctions, American Economic Review, 90, 499-525. 
Riley, J.G. \& Samuelson, W.F. (1981). Optimal Auctions, American Economic Review, 71, 381-392.

Roth, A.E. \& Ockenfels, A. (2002). Last-Minute Bidding and the Rules for Ending SecondPrice Auctions: Evidence from ebay and Amazon Auctions on the Internet, American Economic Review, 92, 1093-1103

Saidi, R. and Marsden, J. (1992). Number of Bids, Number of Bidders and Bidding Behavior in Outer-continental Shelf Oil Lease Auction Markets, European Journal of Operational Research, 58, 3, 335-343.

Sirmans, C.F. and Turnbull, G.K. (1993). Information, Search, and House Prices, Regional Science and Urban Economics 23, 545-557.

Springer, T.M. (1996). Single Family Housing Transactions: Seller Motivations, Price and Marketing Time, Journal of Real Estate Finance and Economics, 13, 237-254.

Stevenson, S. (2008). Modelling Housing Market Fundamentals: Empirical Evidence of Extreme Market Conditions, Real Estate Economics, 36, 1-29.

Stevenson, S., Young, J. \& Gurdgiev, C. (2010). A Comparison of the Appraisal Process for Auction and Private Treaty Residential Sales, Journal of Housing Economics, 19, 157-166.

Taylor, C.R. (1999). Time-on-the-Market as a Sign of Quality, Review of Economic Studies, 66, 555-578.

Toda, Y., Nozdrina, N. \& Maddala, G.S. (1998). The Auction Price of Apartments in Moscow: Hedonic Estimation in Disequilibrium, Economics of Planning, 31, 1-14.

Vickrey, W. (1961). Counterspeculation, Auctions and Competitive Seal Tenders, Journal of Finance, 16, 8-37.

Vincent, D.R. (1995). Bidding off the Wall: Why Reserve Prices may be Kept Secret, Journal of Economic Theory, 65, 575-584.

Waehrer, K., Harstad, R.M. \& Rothkopf, M.H. (1998). Auction Form Preferences of RiskAverse Bid Takers, The Rand Journal of Economics, 29, 179-192.

Wang, S., Jank, A. \& Shmueli, G. (2008). Explaining and Forecasting Online Auction Prices and their Dynamics using Functional Data Analysis, Journal of Business and Economic Statistics, 26, 144-160

Yavas, A. (1992). A Simple Search and Bargaining Model of Real Estate Markets, AREUEA Journal, 20, 533-548.

Yavas, A., Miceli, T.J. \& Sirmans, C.F. (2001). An Experimental Analysis of the Impact of Intermediaries on the Outcome of Bargaining Games, Real Estate Economics, 29, 251-276. 
Yavas, A. \& Yang, S. (1995). The Strategic Role of Listing Price in Marketing Real Estate: Theory and Evidence, Real Estate Economics, 23, 347-368.

Zhang, Y.Y., Gu, J. \& Li, Q. (2011). Nonparametric Panel Estimation of Online Auction Price Processes, Empirical Economics, 40, 51-68. 


\section{The Role of Undisclosed Reserves in English Open Outcry Auctions}

\section{Tables}

Table 1: Summary Statistics

\begin{tabular}{|c|c|c|c|c|c|c|}
\hline & Mean & Median & Minimum & Maximum & $\begin{array}{l}\text { Standard } \\
\text { Deviation }\end{array}$ & Number \\
\hline \multicolumn{7}{|c|}{ Panel A: Overall Sample } \\
\hline Sale Price & 453,044 & 358,000 & 117,100 & $2,750,000$ & 307,445 & 275 \\
\hline Guide Price & 418,679 & 330,000 & 85,000 & $3,200,000$ & 303,525 & 389 \\
\hline Reserve Price & 424,724 & 340,000 & 100,000 & $2,200,000$ & 278,777 & 239 \\
\hline Withdrawn Price & 498,388 & 350,000 & 110,000 & $3,200,000$ & 422,235 & 85 \\
\hline Number in & & 14 & & 70 & 18.26 & \\
\hline Attendance & 20.93 & & 0 & & & 389 \\
\hline Number of Bids & 12.67 & 9 & 0 & 88 & 14.16 & 389 \\
\hline Number of Bidders & 2.21 & 2 & 0 & 10 & 2.07 & 389 \\
\hline No. of Auctions & 2.03 & 2 & 1 & 7 & 1.28 & 389 \\
\hline Bathrooms & 3.79 & 4 & 1 & 5 & 0.83 & 389 \\
\hline Bedrooms & 1.73 & 1.50 & 1 & 8 & 1.13 & 389 \\
\hline \multicolumn{7}{|c|}{ Panel B: Properties Sold at Auction } \\
\hline Sale Price & 462,437 & 364,500 & 133,000 & $2,750,000$ & 312,829 & 198 \\
\hline Guide Price & 353,914 & 290,000 & 85,000 & $2,000,000$ & 232,870 & 198 \\
\hline Reserve Price & 394,493 & 325,000 & 100,000 & $2,200,000$ & 278,927 & 150 \\
\hline \multicolumn{7}{|c|}{ Panel C: Properties Sold at Auction for Whom Reserve Available } \\
\hline Sale Price & 450,327 & 359,000 & 133,000 & $2,750,000$ & 328,450 & 150 \\
\hline Guide Price & 341,700 & 280,000 & 85,000 & $2,000,000$ & 238,185 & 150 \\
\hline Reserve Price & 394,493 & 325,000 & 100,000 & $2,200,000$ & 278,927 & 150 \\
\hline \multicolumn{7}{|c|}{ Panel D: Counts for Dummy Variables } \\
\hline Sold at Auction & & 198 & Parking & & 123 & \\
\hline Withdrawn then Sold & & 77 & Apartment & & 23 & \\
\hline Withdrawn Unsold & & 114 & Terrace/Mews & & 103 & \\
\hline No Bids & & 106 & Semi-Detached & & 91 & \\
\hline Multiple Auctions & & 268 & Detached & & 105 & \\
\hline Front of Room & & 43 & Bungalow & & 67 & \\
\hline Centre of Room & & 97 & Central Dublin & & 25 & \\
\hline Back of Room & & 114 & North City & & 45 & \\
\hline Auctioneer 1 & & 85 & South City & & 155 & \\
\hline Auctioneer 2 & & 111 & South County I & ublin & 128 & \\
\hline Auctioneer 3 & & 127 & Periphery & & 36 & \\
\hline Auctioneer 4 & & 66 & & & & \\
\hline
\end{tabular}

Notes: Table 1 reports summary statistics for some of the key variables. The summary statistics are reported on the basis of the overall sample, for those properties that sold at auction and, in Panel C, for those sold properties for whom all data was available. Panel D displays the number of observations of unity reported for each of the dummy variables used throughout the empirical analysis. 
Table 2: Summary Statistics for Price Premiums

\begin{tabular}{lcccccc}
\hline & Reserve-Open & Reserve-Guide & Open-Guide & Sale-Reserve & Sale-Open & Sale-Guide \\
\hline Average & $24.48 \%$ & $15.15 \%$ & $-6.59 \%$ & $14.18 \%$ & $40.60 \%$ & $31.97 \%$ \\
Count & 199 & 240 & 283 & 150 & 198 & 198 \\
No. Positive & 193 & 227 & 38 & 143 & 197 & 195 \\
No. Zero & 2 & 9 & 45 & 1 & 1 & 0 \\
No .Negative & 4 & 4 & 200 & 6 & 0 & 3 \\
Maximum & $125.00 \%$ & $141.67 \%$ & $108.33 \%$ & $65.22 \%$ & $140.00 \%$ & $192.50 \%$ \\
Minimum & $-10.00 \%$ & $-9.91 \%$ & $-60.00 \%$ & $-14.67 \%$ & $0.00 \%$ & $-53.33 \%$ \\
\hline
\end{tabular}

Notes: Table 2 provides information on the average percentage differences between the various prices used in the study. 
Table 3: Probit Models Examining the Probability of Sale

\begin{tabular}{|c|c|c|c|c|c|c|c|c|}
\hline & \multicolumn{2}{|c|}{ Model I } & \multicolumn{2}{|c|}{ Model II } & \multicolumn{2}{|c|}{ Model III } & \multicolumn{2}{|c|}{ Model IV } \\
\hline & Coefficient & T Statistic & Coefficient & T Statistic & Coefficient & T Statistic & Coefficient & T Statistic \\
\hline Constant & -4.2435 & $-4.5097 * * *$ & 1.2736 & $2.4067 * *$ & 4.1290 & 0.6818 & 2.5740 & 0.3897 \\
\hline Bathrooms & 0.1622 & 1.0037 & 0.0196 & 0.7942 & 0.1893 & 0.7096 & 0.2487 & 0.8355 \\
\hline Bedrooms & 0.0097 & 0.0726 & 0.0327 & 1.5193 & 0.3577 & 1.5831 & 0.2732 & 1.1069 \\
\hline Parking & 0.4678 & 1.5976 & 0.0319 & 0.8506 & 0.6590 & 1.4684 & 0.6585 & 1.3012 \\
\hline Apartment & -0.3052 & -0.4509 & -0.0272 & -0.3265 & -0.6292 & -0.6597 & -0.8021 & -0.7791 \\
\hline Terrace/Mews & 0.2216 & 0.4652 & 0.0324 & 0.5828 & 0.1428 & 0.2025 & 0.2336 & 0.3112 \\
\hline Semi-Detached & 0.0088 & 0.0201 & -0.0008 & -0.0151 & -0.3354 & -0.5239 & -0.0969 & -0.1433 \\
\hline Detached & 0.1290 & 0.3138 & 0.0289 & 0.5391 & 0.3142 & 0.4718 & 0.5955 & 0.8437 \\
\hline Central Dublin & 0.8783 & 1.2731 & 0.0974 & 1.1369 & 1.0496 & 1.1735 & 0.9965 & 0.9956 \\
\hline South City & 0.7793 & $1.7601 *$ & 0.0568 & 1.0299 & 1.1852 & $2.1291 * *$ & 1.2726 & $2.0674 * *$ \\
\hline South County Dublin & 0.6856 & 1.5434 & 0.0339 & 0.5992 & 1.0778 & $1.8530^{*}$ & 1.1084 & $1.6833^{*}$ \\
\hline Periphery & 0.8826 & 1.5610 & 0.0414 & 0.5549 & 0.4996 & 0.6175 & 0.6364 & 0.7292 \\
\hline 1998 & 0.5080 & 1.2985 & -0.0286 & -0.5201 & 0.8064 & 1.3133 & 1.0925 & $1.7281 *$ \\
\hline 1999 & 0.0517 & 0.1380 & -0.0553 & -1.0837 & 0.2129 & 0.3888 & -0.0937 & -0.1575 \\
\hline 2001 & 0.3108 & 0.6068 & 0.0181 & 0.2692 & 0.5702 & 0.6799 & 0.3054 & 0.3483 \\
\hline 2002 & 0.7888 & 1.4152 & 0.0850 & 1.1461 & 1.2889 & 1.3700 & 1.2744 & 1.0941 \\
\hline Auction Attendance & 0.0008 & 0.1080 & -0.0003 & -0.3007 & 0.0073 & 0.7230 & 0.0007 & 0.0598 \\
\hline Number of Bidders & 0.2775 & $1.9106^{*}$ & 0.0971 & $7.2227 * * *$ & 0.5132 & $2.4609 * *$ & 0.3829 & 1.6177 \\
\hline Number of Bids & 0.1709 & $6.1232 * * *$ & 0.0143 & $7.9551 * * *$ & 0.1648 & $4.8812 * * *$ & 0.1736 & $4.7473 * * *$ \\
\hline Multiple Auctions & 0.7947 & $2.3768 * *$ & 0.0829 & $1.9327 *$ & 0.8034 & $1.9109 *$ & 0.6785 & 1.5147 \\
\hline Auctioneer 1 & -0.4724 & -1.1348 & -0.0064 & -0.1151 & -0.3096 & -0.4230 & -0.3706 & -0.4767 \\
\hline Auctioneer 2 & -0.4176 & -1.0044 & -0.0364 & -0.6946 & -0.2713 & -0.3995 & -0.5334 & -0.7374 \\
\hline Auctioneer 3 & -0.1709 & -0.3736 & -0.0250 & -0.4461 & 0.5002 & 0.6421 & 0.0445 & 0.0537 \\
\hline Centre of Room & 0.3961 & 1.5913 & 0.0755 & $2.1630 * *$ & 0.7782 & $2.2189 * *$ & 0.3465 & 0.7972 \\
\hline Rear of Room & -0.0978 & -0.3667 & 0.0160 & 0.4326 & -0.0415 & -0.1132 & 0.0633 & 0.1495 \\
\hline Previous Auction Sold & -0.0988 & -0.2640 & -0.0145 & -0.2981 & -0.0145 & -0.0265 & -0.1037 & -0.1588 \\
\hline Order of Auction & 0.0569 & 0.1622 & -0.0143 & -0.3138 & 0.4532 & 0.9244 & 0.7418 & 1.1650 \\
\hline Guide Price & - & - & -0.1128 & $-2.6032 * * *$ & - & - & - & - \\
\hline Reserve Price & - & - & - & - & -0.8779 & $-1.6468 *$ & - & - \\
\hline Reserve-Guide (\%) & - & - & - & - & -1.2759 & -0.9930 & - & - \\
\hline Opening Bid & - & - & - & - & - & - & -0.6327 & -1.0724 \\
\hline Reserve-Opening Bid (\%) & - & - & - & - & - & - & -3.7565 & $-3.2473 * * *$ \\
\hline McFadden $\mathrm{R}^{2}$ & 0.7261 & & 0.6397 & & 0.7151 & & 0.6629 & \\
\hline Observations & 389 & & 389 & & 239 & & 199 & \\
\hline
\end{tabular}

Notes: Four alternative specifications of a Binary Probit model are estimated where the dependent variable in a binary variable. It takes the value of unity if the property sold at auction and zero otherwise. * indicates significance at $10 \%, * *$ at $5 \%$ and $* * *$ at $1 \%$. 
Table 4: Sale Premiums on Properties Sold at Auction

\begin{tabular}{|c|c|c|c|c|c|c|c|c|c|}
\hline & \multicolumn{3}{|c|}{ Sale-Open Bid (\%) } & \multicolumn{3}{|c|}{ Sale-Guide (\%) } & \multicolumn{3}{|c|}{ Sale-Reserve (\%) } \\
\hline & Coefficient & $\begin{array}{c}\text { Standard } \\
\text { Error }\end{array}$ & T Statistic & Coefficient & $\begin{array}{c}\text { Standard } \\
\text { Error }\end{array}$ & T Statistic & Coefficient & $\begin{array}{c}\text { Standard } \\
\text { Error }\end{array}$ & T Statistic \\
\hline Constant & 0.1122 & 0.0912 & 1.2297 & 0.0772 & 0.0972 & 0.7945 & -0.1154 & 0.0595 & $-1.9394 *$ \\
\hline Bathrooms & -0.0116 & 0.0192 & -0.6054 & -0.0210 & 0.0204 & -1.0247 & -0.0199 & 0.0122 & -1.6286 \\
\hline Bedrooms & 0.0279 & 0.0146 & $1.9146 *$ & -0.0074 & 0.0155 & -0.4736 & 0.0141 & 0.0094 & 1.5033 \\
\hline Parking & -0.0069 & 0.0288 & -0.2381 & -0.0483 & 0.0307 & -1.5724 & -0.0060 & 0.0187 & -0.3233 \\
\hline Apartment & -0.0383 & 0.0687 & -0.5572 & 0.0707 & 0.0731 & 0.9669 & 0.0531 & 0.0436 & 1.2195 \\
\hline Terrace/Mews & -0.0583 & 0.0431 & -1.3543 & -0.0875 & 0.0459 & $-1.9075^{*}$ & 0.0079 & 0.0276 & 0.2876 \\
\hline Semi-Detached & -0.0675 & 0.0404 & $-1.6707^{*}$ & -0.0686 & 0.0431 & -1.5935 & -0.0288 & 0.0269 & -1.0734 \\
\hline Detached & -0.0165 & 0.0425 & -0.3877 & -0.0755 & 0.0453 & $-1.6693 *$ & 0.0202 & 0.0293 & 0.6873 \\
\hline Central Dublin & 0.7031 & 0.0658 & 1.0690 & 0.0167 & 0.0700 & 0.2385 & -0.0605 & 0.0410 & -1.4759 \\
\hline South City & 0.0330 & 0.0402 & 0.8220 & 0.0851 & 0.0428 & $1.9878 * *$ & -0.0220 & 0.0237 & -0.9256 \\
\hline South County Dublin & -0.1892 & 0.0431 & -0.4392 & 0.0587 & 0.0459 & 1.2801 & -0.0096 & 0.0255 & -0.3769 \\
\hline Periphery & -0.0412 & 0.0603 & -0.6826 & -0.0356 & 0.0643 & -0.5545 & -0.0332 & 0.0384 & -0.8634 \\
\hline 1998 & 0.0392 & 0.0402 & 0.9753 & 0.0182 & 0.0428 & 0.4247 & 0.0071 & 0.0289 & 0.2460 \\
\hline 1999 & 0.0199 & 0.0420 & 0.4735 & 0.1042 & 0.0447 & $2.3319 * *$ & 0.0369 & 0.0289 & 1.2792 \\
\hline 2001 & 0.0689 & 0.0610 & 1.1301 & 0.0297 & 0.0650 & 0.4579 & 0.0592 & 0.0425 & $1 . .3929$ \\
\hline 2002 & 0.0296 & 0.0527 & 0.5615 & 0.0800 & 0.0561 & 1.4259 & 0.1003 & 0.0382 & $2.6258 * * *$ \\
\hline Auction Attendance & 0.0015 & 0.0008 & $1.9521 *$ & -0.0004 & 0.0008 & -0.5121 & 0.0010 & 0.0005 & $2.1505 * *$ \\
\hline Number of Bidders & 0.0267 & 0.0093 & $2.8814 * * *$ & 0.0223 & 0.0099 & $2.2667 * *$ & 0.0242 & 0.0062 & $3.9187 * * *$ \\
\hline Number of Bids & 0.0059 & 0.0011 & $5.2421 * * *$ & 0.0065 & 0.0012 & $5.3766 * * *$ & 0.0035 & 0.0007 & $5.2700 * * *$ \\
\hline Multiple Auctions & 0.0037 & 0.0335 & 0.1099 & 0.0167 & 0.0357 & 0.4677 & -0.0058 & 0.0209 & -0.2790 \\
\hline Auctioneer 1 & -0.0041 & 0.0436 & -0.0930 & 0.0499 & 0.0465 & 1.0736 & 0.0388 & 0.0289 & 1.3427 \\
\hline Auctioneer 2 & -0.1246 & 0.0405 & $-3.0794 * * *$ & 0.0305 & 0.0431 & 0.7088 & 0.0552 & 0.0251 & $2.2007 * *$ \\
\hline Auctioneer 3 & -0.0911 & 0.0425 & $-2.1443^{* * *}$ & 0.0873 & 0.0453 & $1.9292 *$ & 0.0228 & 0.0283 & 0.8052 \\
\hline Previous Auction Sold & 0.0145 & 0.0385 & 0.3776 & 0.0665 & 0.0410 & 1.6200 & 0.0628 & 0.0240 & $2.6169 * * *$ \\
\hline Order of Auction & -0.0247 & 0.0350 & -0.7056 & -0.0318 & 0.0372 & -0.8550 & -0.0473 & 0.0212 & $-2.2326 * *$ \\
\hline $\mathrm{R}^{2}$ adjusted & 0.2956 & & & 0.3159 & & & 0.4342 & & \\
\hline Observations & 198 & & & 198 & & & 150 & & \\
\hline
\end{tabular}
Observations $198 \quad 198$
$* *$ at $5 \%$ and $* * *$ at $1 \%$. 
Table 5: Hedonic Model of Sale Price

\begin{tabular}{lccc}
\hline & Coefficient & Standard Error & T Statistic \\
\hline Constant & 11.7933 & 0.2501 & $47.1544^{* * *}$ \\
Reserve-Guide Premium & 0.4773 & 0.2230 & $2.1401^{* *}$ \\
Bathrooms & 0.0773 & 0.0500 & 1.5471 \\
Bedrooms & 0.2022 & 0.0389 & $5.1952^{* * *}$ \\
Parking & 0.0240 & 0.0772 & 0.3112 \\
Apartment & -0.0561 & 0.1785 & -0.3141 \\
Terrace/Mews & -0.1823 & 0.1156 & -1.5769 \\
Semi-Detached & -0.1112 & 0.1105 & -1.0063 \\
Detached & 0.1572 & 0.1222 & 1.2866 \\
Central Dublin & 0.2116 & 0.1686 & 1.2551 \\
South City & 0.2168 & 0.1001 & $2.1660 * *$ \\
South County Dublin & 0.0672 & 0.1058 & 0.6353 \\
Periphery & 0.1106 & 0.1574 & 0.7029 \\
1998 & -0.4926 & 0.1184 & $-4.1602^{* * *}$ \\
1999 & -0.2458 & 0.1183 & $-2.0784^{* *}$ \\
2001 & 0.3589 & 0.1741 & $2.0615 * *$ \\
2002 & 0.4445 & 0.1573 & $2.8267 * * *$ \\
Auction Attendance & 0.0009 & 0.0019 & 0.4796 \\
Number of Bidders & 0.0359 & 0.0253 & 1.4166 \\
Number of Bids & 0.0003 & 0.0028 & 0.1229 \\
Multiple Auctions & 0.0011 & 0.0857 & 0.0127 \\
Auctioneer 1 & 0.2863 & 0.1182 & $2.4223 * *$ \\
Auctioneer 2 & 0.0288 & 0.1029 & 0.2793 \\
Auctioneer 3 & 0.0619 & 0.1162 & 0.5332 \\
Previous Auction Sold & 0.0440 & 0.0983 & 0.4479 \\
Order of Auction & 0.0134 & 0.0869 & 0.1539 \\
\hline R adjusted & 0.5626 & & \\
Observations & 198 & & \\
\hline Notes: A hedonic mo & & \\
\hline
\end{tabular}

Notes: A hedonic model is estimated with the dependent variable being the log of the sale price achieved. The observations included in this specification are solely those properties that were successfully sold at auction. $*$ indicates significance at $10 \%, * *$ at $5 \%$ and $* * *$ at $1 \%$. 


\section{Endnotes:}

${ }^{1}$ See also papers such as Maskin \& Riley (1984), Waehrer et al. (1998) and Haile \& Tamer (2003) with respect to the issue of risk aversion and the setting of optimal reserve prices.

${ }^{2}$ This proxy was not adopted in the current study for three primary reasons. Firstly, the undisclosed reserve was available. Secondly, the current lack of a comparable sample of pure private treaty sales limits the ability to provide an estimate of market value. Finally, the opening bid, as we will see, bears limited relation to the valuation of the property.

${ }^{3}$ There is in addition a general literature that has examined the bidding process and how the arrival of bids can influence the outcome of an auction. The development of online auctions has led to a large number of papers to have considered such issues in recent years (e.g. Bajari \& Hortacsu, 2003, 2004; Roth \& Ockenfels, 2002; Wang et al., 2008; Zhang et al., 2011)

${ }^{4}$ On a more general note Chow et al. (2011) also support the previously cited work relating to the importance of market conditions and that auctions are more likely to outperform during periods of strong house price appreciation.

${ }^{5}$ See also papers such as Yavas (1992), Sirmans \& Turnbull (1993), Chen \& Rosenthal (1996a, 1996b), Springer (1996), Knight et al. (1998), Arnold (1999), Taylor (1999), Knight (2002), Anglin et al. (2003).

${ }^{6}$ Part of the conditions agreed to when obtaining the data was that the auction house remain anonymous. Furthermore, the sensitive nature of the data meant that no data after 2002 was released.

${ }^{7}$ All of the properties sold through auction were done so with an undisclosed reserve. For those properties for which this information was not available it is simply that the information was not recorded in the auction book. This is why when we include the reserve as a variable in any of the empirical models we do so with a curtailed sample.

${ }^{8}$ The withdrawn price data only uses information from those auctions where there was actual bidding. In a large number of cases properties were withdrawn after no bidding. Hence in those cases we have no actual withdrawn price or an opening bid. Indeed, the only reliable prices are the listing price and the reserve where available.

${ }^{9}$ Note that whilst prices were denominated in Irish Pounds prior to the introduction of the coinage of the Euro in January 2002 all prices used in the study are quoted in Euro's.

${ }^{10}$ On a more general setting Yavas et al. (2001) consider the role of opening bids in the context of negotiated sales. This experimental paper includes initial opening bids from both the buyer and seller.

${ }^{11}$ For a broad consideration of alternative methodological frameworks adopted in the auction literature see Paarsch \& Han (2006). Some of this literature has specifically considered the examination of auction bidding when the number of bidders is unknown (e.g. An et al., 2010; Guerre et al., 2000; Li et al, 2002; Hendricks et al., 2003). We do however have the benefit of knowing this information. This does make the empirical modelling easier and illustrates the richness of the data available.

${ }^{12}$ In addition to the previously cited papers such as Vickrey (1961), Holt (1979), Harris \& Raviv (1981) and McAfee \& McMillan (1987) in relation to the theoretical arguments as to 
the role of bids in auction prices, see also to more recent papers such as Mayer (1995) and Goeree \& Offerman $(2002,2003)$.

${ }^{13}$ As previously noted there is a similar argument relating to the setting of list prices with respect to negotiated sales in housing. See for example Haurin (1988), Mayer (1995), Genesove \& Mayer (1997) and Merlo \& Ortalo-Magne (2004).

${ }^{14}$ The examination of the reserve relates purely to the presence of one and its level. As noted previously, all of the properties have a reserve price that is undisclosed. Any indirect disclosure by the auctioneer is, as previously stated, at their discretion not the vendor's and does not necessarily occur at the point at which the reserve is exceeded.

${ }^{15}$ See Stevenson (2008) for a broader discussion of market conditions in the Irish market during this period.

${ }^{16}$ Informal inquiries would confirm this. The person in question was the senior auctioneer and was more likely to preside over highly valued properties. 